been introduced. Many neonatal units use these formulas to complement breast milk fed to infants but our findings illustrate a potential hazard in this approach. Despite an increase in absolute calcium intake, the additional phosphorus to correct the low plasma inorganic phosphorus and presumed total body phosphorus depletion caused symptomatic hypocalcaemia.

The molar calcium to phosphorus ratio may be as important as the absolute concentration of these minerals in the correction of any deficiency. There may, however, be a delay in maturation of $1 \alpha$ hydroxylase enzyme in the low birthweight baby. ${ }^{7}$ Further data are needed before preterm infants can be safely given routine calcium and phosphorus supplements.

We thank Professor D Barltrop for advice.

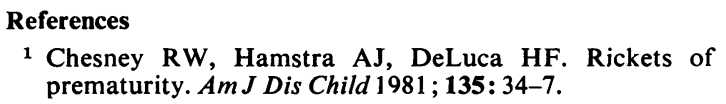

2 Forbes GB. Human milk and the small baby. Am J Dis Child 1982; 136: 577-8.

3 Kovar I, Mayne P, Barltrop D. Plasma alkaline phosphatase activity: a screening test for rickets in preterm neonates. Lancet 1982; i : 308-10.

4 Eek S, Gabrielsen LH, Halvorsen S. Prematurity and rickets. Pediatrics 1957; 20: 63-77.

5 Greer FR, Steichen JJ, Tsang RC. Calcium and phosphate supplements in breast milk-related rickets. $\mathrm{Am} \mathrm{J}$ Dis Child 1982; 136: 581-3.

- Brewer ED, Winslow CS, Dell L, Conley SB, Morriss FH. Role of intakes of vitamin D, calcium and phosphorus in rickets of growing very low birthweight infants. The 5th Workshop Vitamin D, Williamsburg, Virginia, February 1982.

7 Seino Y, Ishii T, Shimotsuji T, Ishida M, Yabuuchi H. Plasma active vitamin $\mathrm{D}$ concentration in low birthweight infants with rickets and its response to vitamin D treatment. Arch Dis Child 1981; 56: 628-32.

Correspondence to Dr llya Kovar, Department of Child Health, Westminster Children's Hospital, Vincent Square, London SW1 P 2NS.

Received 12 April 1983

\title{
Neonatal paracetamol poisoning: treatment by exchange transfusion
}

\author{
S LEDERMAN, W J FYSH, M TREDGER, AND H R GAMSU \\ Department of Child Health and Liver Unit, King's College Hospital, London
}

SUMMARY The metabolism and excretion of paracetamol was studied in an infant of 29 weeks' gestation who was exposed to the drug when his mother ingested $32.5 \mathrm{~g} 16$ hours before delivery. We have confirmed that sulphation is the major pathway and that the mixed function oxidase system is sufficiently active at this gestational age to produce hepatotoxic metabolic products. As most of the recognised drug treatments for paracetamol poisoning seemed unsuitable in this case, the infant was treated with exchange transfusions.

We report a case of paracetamol poisoning in an infant of 29 weeks' gestation whose mother ingested paracetamol before delivery. Studies have shown that the human neonate can conjugate paracetamol predominantly by sulphation and also by glucuronidation. ${ }^{12}$ Human fetal liver cells can also oxidise paracetamol by the mixed function oxidase system to the reactive arylating intermediate and unless this latter substance is conjugated with glutathione, liver necrosis is likely. Although there are no data concerning the human fetus after 23 weeks'gestation, ${ }^{3}$ oxidation is slower than in the adult liver and increases with gestational age. Paracetamol poisoning in a premature infant in vivo has never been described and thus there are no guidelines for treatment. In this infant we performed exchange transfusion of whole blood because of the risk of severe hepatic necrosis.

\section{Case report}

A 22 year old Caucasian mother had a normal third pregnancy until 29 weeks' gestation when she took a drug overdose because of acute depression. She ingested 50 tablets of Anadin (aspirin $325 \mathrm{mg}$, caffeine $15 \mathrm{mg}$, and quinine sulphate $1.0 \mathrm{mg}$ ) 33 hours before delivery and 65 Hedex (paracetamol $500 \mathrm{mg}) 16$ hours before delivery. Severe vomiting occurred and premature labour began 10 hours after she had taken the paracetamol. Six hours before delivery salicylate concentations were reported to be in the non-toxic range but her paracetamol value was $1056 \mu \mathrm{mol} / 1(15.95 \mathrm{mg} / 100 \mathrm{ml})$, indicating severe poisoning and she was therefore given 1 dose of methionine, $2.5 \mathrm{~g}$ orally. ${ }^{4}$ She had no clinical signs of liver damage after delivery, but 50 hours after the ingestion of paracetamol (Table 1) her aspartate transaminase activity rose to a maximum of $4300 \mathrm{IU} / 1$, bilirubin to $30 \mu \mathrm{mol} / 1$ $(1.75 \mathrm{mg} / 100 \mathrm{ml})$ and prothrombin time to 22 seconds (control 13). Her liver function had returned to normal by 126 hours and there were no sequelae. 
Table Paracetamol blood values and liver function test results in infant and mother (in parentheses) in relation to time and exchange transfusions

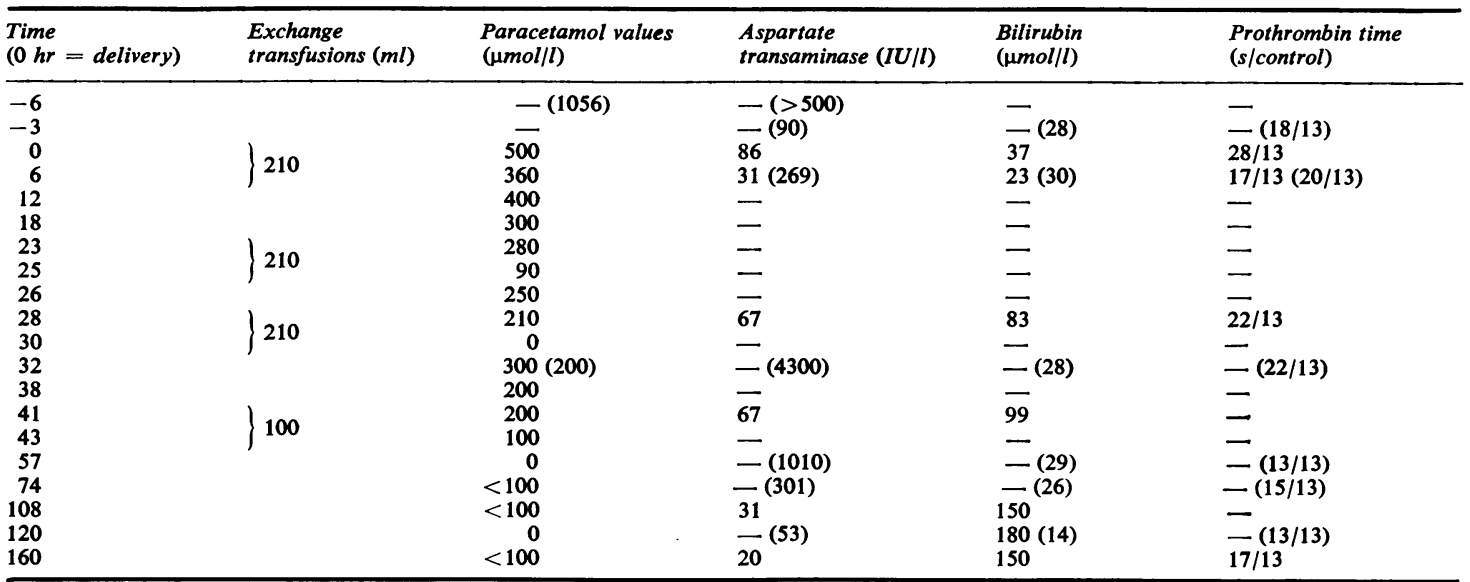

Conversion: SI to traditional units-paracetamol: $1 \mu \mathrm{mol} / 1 \approx 0.0151 \mathrm{mg} / 100 \mathrm{ml}$; bilirubin $1 \mu \mathrm{mol} / 1 \approx 0.058 \mathrm{mg} / 100 \mathrm{ml}$.

Her psychosocial problems made follow up of mother and child extremely difficult.

The baby girl, birthweight $1.22 \mathrm{~kg}$ (25th centile), was born by spontaneous vertex delivery. There were no malformations and Dubowitz assessment confirmed the gestational age as calculated from the last menstrual period. The Apgar scores were 4 at 1 minute and 7 at 5 minutes. Endotracheal intubation was electively performed at 90 seconds. She subsequently developed hyaline membrane disease and required intermittent positive pressure ventilation for 4 days, continuous positive airways pressure for 2 days, and an increase in inspired oxygen concentration for a further 3 days. The cord blood paracetamol value was $500 \mu \mathrm{mol} / 1(7.55 \mathrm{mg} / 100 \mathrm{ml})$ and no salicylate was detected. The aspartate transaminase was $86 \mathrm{IU} / \mathrm{l}$, bilirubin $37 \mu \mathrm{mol} / \mathrm{l}$ $(2.2 \mathrm{mg} / 100 \mathrm{ml})$, and prothrombin time 28 seconds (control 13). She underwent exchange transfusions with whole donor blood at $4,23,28$, and 41 hours after delivery (Fig. 1). Penicillin and gentamicin were given prophylactically from day 0 to 7 . Clinical jaundice was apparent on day 5 with a bilirubin value of $180 \mu \mathrm{mol} / 1(10.5 \mathrm{mg} / 100 \mathrm{ml})$ (conjugated $6 \mu \mathrm{mol} / \mathrm{l})$, haemoglobin $12 \cdot 2 \mathrm{~g} / \mathrm{dl}$, white blood count $6.5 \times 10^{9} / 1\left(6500 / \mathrm{mm}^{3}\right)$, platelets $155 \times 10^{9} / 1$ $\left(155 \mathrm{000} / \mathrm{mm}^{3}\right)$ and normal blood film. Urinary reducing substances were negative. The bilirubin value fell to $90 \mu \mathrm{mol} / 1(5.2 \mathrm{mg} / 100 \mathrm{ml})$ by day 8 and the jaundice was attributed to her prematurity. On day 11 she became unwell with bile stained vomiting and tachypnoea. Examination of the cerebrospinal fluid and examination of the blood culture did not show infection but she was immediately treated with ampicillin and gentamicin which was continued for 4 days. She subsequently remained well and was discharged back to the referring hospital at the age of 22 days when she weighed $1.4 \mathrm{~kg}$. Her course was complicated further by a respiratory infection treated with penicillin and

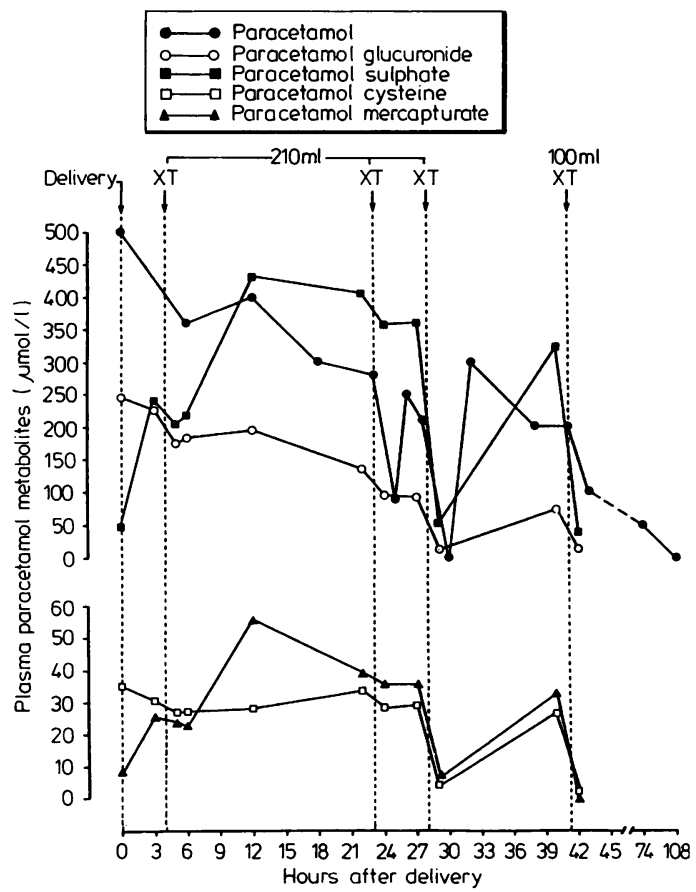

Fig. 1 Blood values of paracetamol and its metabolites in infant in relation to age and exchange transfusions $(X T)$. 
gentamicin. She was discharged at the age of 54 days when her weight was $2.35 \mathrm{~kg}$. She failed to attend an outpatient appointment and died unexpectedly at the age of 106 days. The coroner's post mortem examination showed no definite cause of death, the only positive findings being many petechiae on the surface of the thymus, heart, and lungs.

\section{Discussion}

The infant's mother had a toxic blood concentration of paracetamol and she was fortunate to escape liver damage. The giving of methionine may have contributed to this favourable outcome. Methionine was not used in the infant as more than 12 hours had elapsed since the mother's ingestion of paracetamol and we knew of no reports of the use of this potentially toxic drug in the neonatal period.

Paracetamol is less toxic in the newborn mouse than in the adult because adequate glutathione stores are present before the ability to produce the toxic metabolite develops. ${ }^{5}$ It is unclear, however, whether the same conditions prevail in the human neonate. In this case the infant was exposed to potentially toxic blood values of paracetamol but suffered no liver damage and it seemed important to establish the contribution of exchange transfusions to this outcome.

Plasma paracetamol concentrations did not decrease continuously in the infant but showed a rebound effect after each of the first 3 exchange transfusions. This was probably because paracetamol sequestered in the tissues was released after each exchange before being subsequently removed from the circulation. Despite exchange transfusion, the plasma half life of paracetamol (26 hours) was considerably prolonged.

The plasma values of paracetamol and its metabolites are shown in Fig. 1. These were separated and measured by reverse phase high performance liquid chromatography using $0 \cdot 1 \mathrm{M}$ potassium dihydrogen phosphate $/ 0.1 \%$ formic acid $/ 0.45 \%$ isopropanol as elution solvent and $\mathrm{N}$-acetyl-3 aminophenol as internal standard. The finding of a fall in glucuronide conjugates similar to that of the parent drug suggests that this mainly reflects maternal metabolism. The rise in sulphate conjugates, however, shows that this infant of 29 weeks' gestation was able to conjugate paracetamol by sulphatation. Cysteine and mercapturate conjugates were found to increase as well, thus supporting the in vitro findings that the mixed function oxidase system is active in the preterm infant and glutathione is available to conjugate with the metabolites produced. ${ }^{3}$ If exchange transfusions had not been performed glutathione stores might have been depleted leading to hepatic necrosis.

Dr Fysh is supported by the National Medical Research Fund.

\section{References \\ 1 Miller RP, Roberts RJ, Fischer LJ. Acetaminophen elimination kinetics in neonates, children, and adults. Clin Pharm Ther 1976; 19: 284-94. \\ ${ }^{2}$ Levy G, Khanna NN, Soda DM, Tsuzuki O, Stern L. Pharmacokinetics of acetaminophen in the human neonate: formation of acetominophen glucuronide and sulphate in relation to plasma bilirubin concentration and D-glucaric acid excretion. Pediatrics 1975; 55: 818-25. \\ 3 Rollins DE, Von Bahr C, Glaumann $H$, Moldeus $P$, Rane A. Acetaminophen: potentially toxic metabolite formed by human fetal and adult liver microsomes and isolated fetal liver cells. Science 1979; 205: 1414-6. \\ 4 Prescott LF, Wright N, Roscoe P, Brown SS. Plasma- paracetamol half-life and hepatic necrosis in patients with paracetamol overdosage. Lancet 1971; i: 519-22. \\ 5 Hart JG, Timbrell JA. The effect of age on paracetamol hepatotoxicity in mice. Biochem Pharmacol 1979; 28: 3015-7.}

Correspondence to Dr S Lederman, Department of Child Health, King's College Hospital, Denmark Hill, London SE5 8RX.

Received 11 March 1983

\title{
Central venous catheters for out-patient management of malignant disorders
}

\author{
M STOCKWELL, M ADAMS, M ANDREW, G CAMERON, AND K PAI \\ The Departments of Pediatrics and Surgery, McMaster University Health Sciences Centre, \\ Hamilton, Ontario, Canada
}

SUMMARY The use of tunnelled central venous catheters in children with malignant disorders is an effective and safe way of giving out-patient chemotherapy and supportive care. The benefits include ready venous access, ease of administration of chemotherapy, decreased time spent in the outpatient clinic, and less anticipatory vomiting and emotional trauma for patients, parents, and staff.
Children requiring intensive intravenous chemotherapy for the management of malignant disorders undergo physical and psychological trauma because of repeated venepuncture. Prolonged and repeated use of peripheral veins may also result in local pain from thrombosis or drug extravasation. Indwelling right atrial catheters have been used for giving total parenteral nutrition ${ }^{12}$ and for facilitating bone marrow transplantation, ${ }^{3}$ in-patient treatment 